\title{
KARAKTERISTIK CENDAWAN DARK SEPTATE ENDOPHYTE (DSE) PADA AKAR TANAMAN JAGUNG DAN PADI
}

\author{
Dezi Handayani \\ Jurusan Biologi FMIPA Universitas Negeri Padang \\ e-mail: dzhandayani@yahoo.com
}

\begin{abstract}
Plant roots host a variety of fungi. The association between fungi and plant roots categorized to mycorrhizal and non-mycorrhizal. One important group of non-mycorrhizal symbioses is the dark septate endophytes (DSE) that colonize plant roots and form characteristic intracellular structures-melanized hyphae and microsclerotia. Compared to better known mycorrhizal symbioses or the vertically transmitted systemic foliar endophytes, the DSE have received very little attention. So, the research was conduct to analize the characteristics of DSE in roots system of maize and rice plant. The roots sample was taken from maize and rice fields around Kuranji District, Padang. Occurance of DSE was observe by tryphan blue staining $(0.05 \%)$ using digital microscope. DSE was found in $65 \%$ of the total of maize root segments observed and $30 \%$ for roots of rice plant. DSE occurs in corn roots system as brown hyphae inter-and intracellularly and dark-brown microsclerotia intracellularly. The smaller microsclerotia found in rice roots system and absorbed tryphan blue, then appeared as blue color. The melanized hyphae found in rice roots system was different with those found in maize root.
\end{abstract}

Keywords: Dark Septate Endophyte, plant root, microsclerotia, melanized hyphae

\section{PENDAHULUAN}

Dark septate endophytes (DSE) merupakan cendawan non-mikoriza yang mengkolonisasi akar. Mandyam \& Jumpponen (2015) mendefinisikan DSE sebagai cendawan yang mengkolonisasi akar tanaman dengan ciri khas struktur hifa internal berupa hifa termelanisasi berwarna gelap dan mikrosklerosia.

Kolonisasi DSE dilaporkan terjadi pada sekitar 600 spesies tanaman meliputi 320 genus dan 114 famili serta tersebar luas mulai dari daerah tropis sampai kutub dan juga pegunungan (Jumpponen \& Trappe,
1998). DSE juga telah ditemukan pada tanaman Shorea selanica (meranti) yang termasuk ke dalam famili Dipterocarpaceae (Handayani, 2016). DSE sering ditemukan bersama-sama dengan cendawan mikoriza (Jumpponen \& Trappe, 1998), terutama pada lingkungan yang mengalami cekaman abiotik berat (Knapp et.al. 2015), bahkan pada daerah yang mengalami kekeringan dan suhu dingin yang ekstrem (Zhang et al. 2011).

DSE telah diketahui mempunyai berbagai peranan menguntungkan terhadap tanaman, diantaranya sebagai penyedia nutrisi baik organik maupun anorganik, 
meningkatkan toleransi tanaman inang terhadap tekanan lingkungan dan serangan patogen, serta memodulasi pembentukan CMA pada tanaman inang. Selain itu DSE juga berpotensi menghasilkan senyawa metabolit sekunder toksik bagi herbivora sehingga dapat meningkatkan performa tanaman inang (Mandyam \& Jumpponen, 2005).

Usuki \& Narisawa (2007) melaporkan bahwa Heteroconium chaetospira memiliki kemampuan yang lebih baik untuk menyediakan nitrogen dibandingkan dengan kemampuan tanaman untuk melakukan mineralisasi dari sumber nitrogen organik yang tersedia dalam tanah. Hou \& Guo (2008) menyatakan bahwa inokulasi DSE pada sistem perakaran bibit Dendrobiumnobile mampu meningkatkan tinggi tanaman, diameter batang serta jumlah dan biomassa akar. DSE juga dilaporkan memiliki kemampuan untuk melarutkan fosfat, menyediakan karbon serta meningkatkan biomassa akar dan batang (Barrow \& Osuna, 2002).

Jumpponen \& Trappe (1998) menyatakan bahwa diantara 144 famili tanaman yang menjadi inang DSE yang telah dipelajari, Gramineaceae dikolonisasi oleh 59 jenis DSE yang berbeda dan menduduki peringkat teratas. Oleh karena itu, jenis-jenis tanaman yang tergolong dalam famili Gramineaceae dapat digunakan sebagai sumber habitat untuk mengisolasi dan mempelajari karakteristik DSE dari alam. Padi dan jagung merupakan jenis tanaman yang tergolong dalam famili Gramineaceae dan mudah ditemukan di berbagai tempat sehingga dapat dijadikan sebagai sumber inang untuk mengisolasi DSE.

Dengan dasar pengetahuan seperti yang telah diuraikan di atas, maka ada peluang untuk mempelajari karakteristik dan mendapatkan cendawan dark sepatate endophyte dari kedua jenis tanaman yang telah disebutkan di atas. DSE yang ditemukan bisa dimanfaatkan sebagai
E-ISSN : 2549-7464, P-ISSN : 1411-3724

cendawan potensial untuk berbagai keperluan, misalnya potensi untuk melarutkan fosfat, menghasilkan metabolit komersial atau senyawa antibakteri.

\section{METODE PENELITIAN}

\section{Tempat Penelitian}

Penelitian dilaksanakan pada bulan April sampai November 2016 di Laboratorium Mikrobiologi, Jurusan Biologi, FMIPA, Universitas Negeri Padang.

\section{Bahan}

Bahan utama yang digunakan dalam penelitian ini adalah sampel akar tanaman padi dan jagung, pewarna biru tripan $0.05 \%$, dan media Potato Dextrose Agar (PDA)

\section{Prosedur Penelitian}

Penelitian dilakukan dalam beberapa tahapan sebagai berikut:

\section{a. Pengambilan sampel akar tanaman padi dan jagung.}

Sampel akar tanaman padi dan jagung yang akan dijadikan sampel diambil secara purposive. Akar tanaman sampel dipilih dari tanaman yang sudah tua dengan alasan untuk memperbesar kemungkinan menemukan cendawan DSE. Sampel akar yang diambil adalah bagian ujung akar yang banyak memiliki rambut akar dan dipotong kurang lebih sepanjang $10 \mathrm{~cm}$ dari ujung. Tempat pengambilan akar tanaman sampel adalah Kecamatan Kuranji, Padang. Sampel akar padi dan jagung diambil pada tanggal 23 Juli 2016.

\section{b. Pengamatan DSE pada sampel akar menggunakan analisis pewarnaan biru tripan}


Keberadaan cendawan DSE pada akar tanaman sampel diketahui dengan cara mewarnai sebagian akar dengan pewarna biru tripan $0.05 \%$. Metode pewarnaan akar mengikuti prosedur Kormanick \& McGraw (1982). Akar tanaman dipisahkan dari tanah dengan hati-hati agar sistem perakaran tidak rusak. Akar dicuci dengan air mengalir selama 10 menit untuk menghilangkan sisa tanah dan kotoran yang menempel pada akar dan setelah itu dipotong dengan ukuran $1 \mathrm{~cm}$.

Potongan akar direndam dalam larutan $\mathrm{KOH} 10 \%$ pada suhu $90^{\circ} \mathrm{C}$ selama 10-15 menit untuk menghilangkan isi sel. Apabila selama proses tersebut warna akar masih gelap, maka perendaman dapat diperpanjang sampai diperoleh akar yang transparan. $\mathrm{KOH}$ dibuang dan sisanya dihilangkan dengan membilas akar dengan akuades sebanyak 3-5 kali. Akar direndam dalam larutan HCL 1N selama 1 malam, selanjutnya diwarnai dengan pewarna biru tripan $0.05 \%$ selama 20-30 menit. Akar yang telah diwarnai disimpan dalam larutan gliserol $50 \%$ dan diamati menggunakan mikroskop cahaya.

Jumlah potongan akar untuk setiap jenis tanaman yang diamati adalah 40 segmen $(40 \times 1 \mathrm{~cm})$. Adanya DSE pada akar tanaman sampel dicirikan dengan pertumbuhan hifa berwarna gelap dan struktur seperti sklerosium di jaringan akar melalui pengamatan di bawah mikroskop. Ciri-ciri DSE yang terlihat dicatat dan dibuat dokumentasi menggunakan kamera digital dengan resolusi memadai. persentase potongan akar yang membawa DSE dihitung untuk melihat persentase kolonisasi.

\section{c. Isolasi DSE dari Sistem Perakaran Padi dan Jagung}

Isolasi DSE dari akar tanaman dilakukan untuk mengamati karakteristik hifa lebih lanjut menggunakan media PDA. Akar yang diduga mengandung DSE
E-ISSN : 2549-7464, P-ISSN : 1411-3724

dibersihkan dari sisa tanah dengan cara dicuci menggunakan air mengalir selama kurang lebih 10 menit. Selanjutnya akar dipotong dengan ukuran kurang lebih $1 \mathrm{~cm}$ dan direndam dalam EtOH 70\% selama dua menit. EtOH dibuang dan dilanjutkan dengan perendaman dalam larutan Chlorine $1 \%$ selama 2 menit. Akar dibilas sebanyak 2-3 kali dengan akuades steril, lalu dikeringkan dengan tissue steril selama 3-4 jam. Akar yang sudah steril dan kering ditanam di media PDA dan diinkubasi pada suhu ruang. Penanaman dilakukan secara duplo untuk masing-masing jenis sampel tanaman. Koloni cendawan yang lambat pertumbuhannya diduga sebagai DSE dan dimurnikan menggunakan media yang sama. Koloni DSE diamati secara mikroskopik menggunakan mikroskop cahaya.

\section{HASIL DAN PEMBAHASAN}

Persentase akar tanaman jagung yang membawa DSE adalah sebesar 65\% (26 dari 40 potongan akar) lebih besar dari persentase DSE pada akar tanaman padi yang hanya sebesar 30\% (12 dari 40 potongan akar). Jumlah sel yang dikolonisasi pada kedua tanaman beragam. Perbedaan persen kolonisasi ini terjadi diduga karena pengaruh kadar air tanah tempat inang tumbuh. DSE lebih umum ditemukan di tanah yang kering dan mengalami cekaman abiotik. Hal ini sejalan dengan pendapat Zhang et al. (2011).

Ada beberapa struktur DSE yang teramati pada akar tanaman jagung dan padi. Struktur umum yang menjadi ciri khas DSE ditemukan pada kedua tanaman inang, yaitu mikrosklerosium dan hifa bersekat termelanisasi.

Ada perbedaan antara mikrosklerosium yang ditemukan pada akar jagung dan padi. Akar jagung umumnya membawa DSE berukuran besar dan berwarna coklat (Gambar 1a). Sebagian sel akar terlihat penuh berisi mikrosklerosium 
dan ada pula sel yang baru terisi beberapa mikrosklerosium dengan hifa yang masih terlihat dengan jelas (Gambar 1b). Akar tanaman padi membawa mikrosklerosium dengan ukuran yang lebih kecil dan tidak menyerap pewarna biru tripan (Gambar 1c). Perbedaan ini mengindikasikan bahwa mikrosklerosiun pada akar tanaman jagung sudah mengalami melanisasi sementara DSE akar tanaman padi belum. Dapat dikatakan bahwa DSE yang mengkolonisasi akar padi baru sampai pada tahap awal perkembangan (Lukešová et al. 2015). Selain itu, Yuan et al. (2010) juga menyatakan bahwa jumlah dan ukuran mikrosklerosium berhubungan dengan tingkat perkembangan DSE dalam akar tanaman inang.
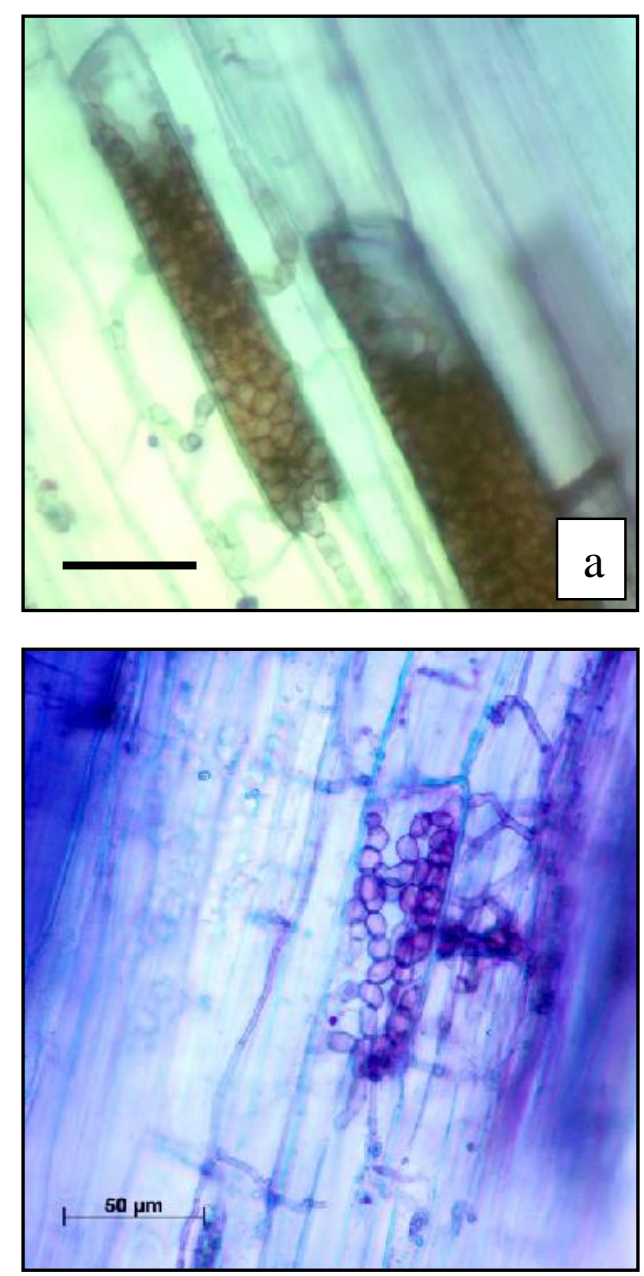

E-ISSN : 2549-7464, P-ISSN : 1411-3724



Gambar 1. Mikrosklerosium yang terdapat pada akar jagung (a, b) dan akar padi (c). Bar $=50 \mu \mathrm{m}$.

Hifa termelanisasi interselular ditemukan pada akar jagung. Hifa ini memiliki sel-sel yang ramping dan panjang (Gambar 2a). Hifa intraselular berukuran besar juga ditemukan bersebelahan dengan dengan hifa termelanisasi. Kemungkinan hifa ini merupakan hifa cendawan endofit lain yang tidak tergolong ke dalam kelompok DSE. Hifa ini kemungkinan besar merupakan hifa dari cendawan mikroriza karena di dalam akar (baik padi maupun jagung) juga ditemukan vesikula yang menjadi ciri dari cendawan mikoriza Arbuskula (Gambar tidak ditampilkan).

Keberadaan DSE dan CMA sekaligus, tidak memperlihatkan gejala sakit pada kedua jenis tanaman yang diamati. Tanaman terlihat sehat dengan struktur akar yang baik. Kemungkinan DSE dan CMA memiliki sinergisme yang baik dalam mendukung pertumbuhan tanaman. (Jumpponen et al.,1998; Scervino et al., 2009; Usuki \& Narisawa, 2007). 

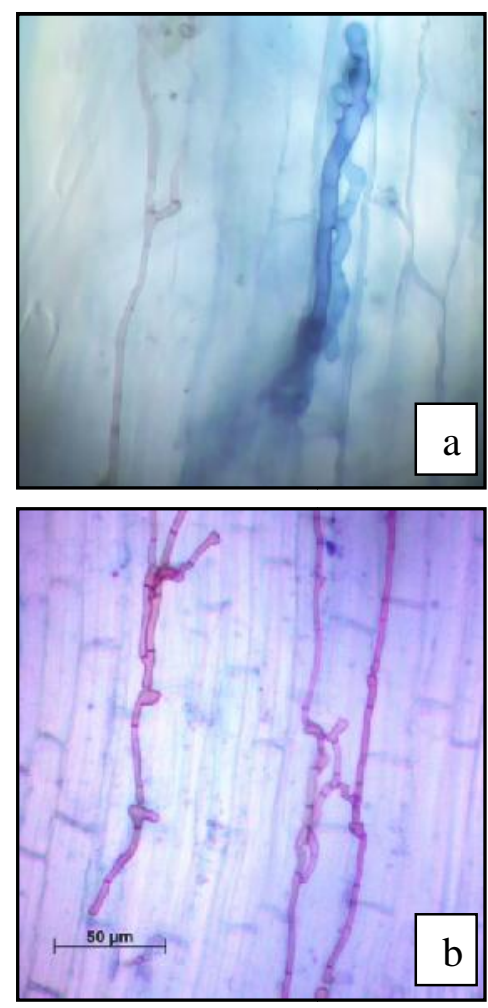

Gambar 2. Struktur hifa termelanisasi. a) pada akar jagung dan b) pada akar padi. Bar $=50$ $\mu \mathrm{m}$

Struktur hifa termelanisasi yang ditemukan pada akar tanaman padi berukuran lebih besar dengan sel-sel pendek dan tidak teratur (Gambar 2b). Hifa termelanisasi pada akar tanaman padi ini tumbuh baik secara ektra, inter maupun intraselular.

Selain mikrosklerosium dan hifa bersekat termelanisasi, struktur mirip klamidospora juga ditemukan baik pada akar tanaman jagung, maupun akar tanaman padi. Struktur ini berbentuk bulat dengan banyak granul di bagian dalam (Gambar 3a) sedangkan pada akar padi tidak memiliki granul (Gambar 3b).

Hifa DSE dapat dengan mudah dibedakan dari hifa cendawan endofit akar yang lain karena tidak menyerap pewarna yang diberikan (Mandyam \& Jumpponen 2005; Silvani et al., 2008). Hifa DSE berwarna gelap sebagai tanda bahwa dinding hifa mengalami melanisasi dan
E-ISSN : 2549-7464, P-ISSN : 1411-3724

dapat tumbuh secara inter atau intraselular di epidermis atau korteks akar.

Ukuran dan bentuk mikrosklerosium DSE beragam (Zhang et al. 2011) Dalam penelitian ini mikrosklerosium yang ditemukan ada yang berukuran cukup besar dan berwarna gelap dan ada pula kecil dan hialin. Perkembangan yang seperti ini menunjukkan bahwa formasi dan deposisi melanin dalam dinding sel DSE terjadi secara bertahap dan kemungkinan hal ini berhubungan dengan mekanisme perlindungan cendawan dari kondisi lingkungan yang tidak menguntungkan seperti kekeringan, temperatur tinggi dan radiasi (Butler and Day, 1998; Robinson, 2001; Vrålstad et al., 2002; Suryanarayanan et al., 2004; Addy et al., 2005; Zhang et al., 2011; Seerangan \& Thangavelu, 2014).

Hifa hialin (tidak menyerap pewarna biru tripan) diasumsikan berguna sebagai tempat terjadinya pertukaran nutrisi dan bahan-bahan lain antara inang dan DSE (Barrow and Aaltonen, 2001)

Mikrosklerosium bergumpal mirip otak juga ditemukan dalam penelitian ini (Gambar 3c). Struktur ini sedikit berbeda dengan mikrosklerosium yang lainnya. Beberapa peneliti juga menemukan struktur seperti ini, diantaranya adalah Horton et al., (1998); Barrow and Aaltonen, (2001); Girlanda et al., (2002) dan Rains et al., (2003). Sejauh ini belum ada laporan mengenai fungsi hifa yang mengalami dismorfosis ini. Namun, Zhang et al., (2011) berpendapat bahwa adanya polimorfisme struktur DSE berkaitan dengan perbaikan adaptasi DSE terhadap stress lingkungan.

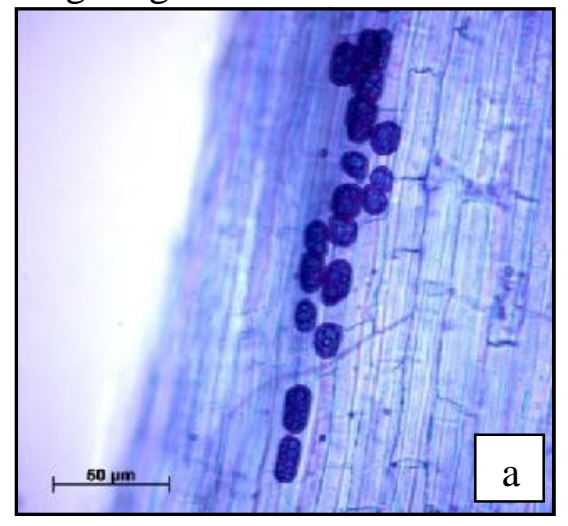



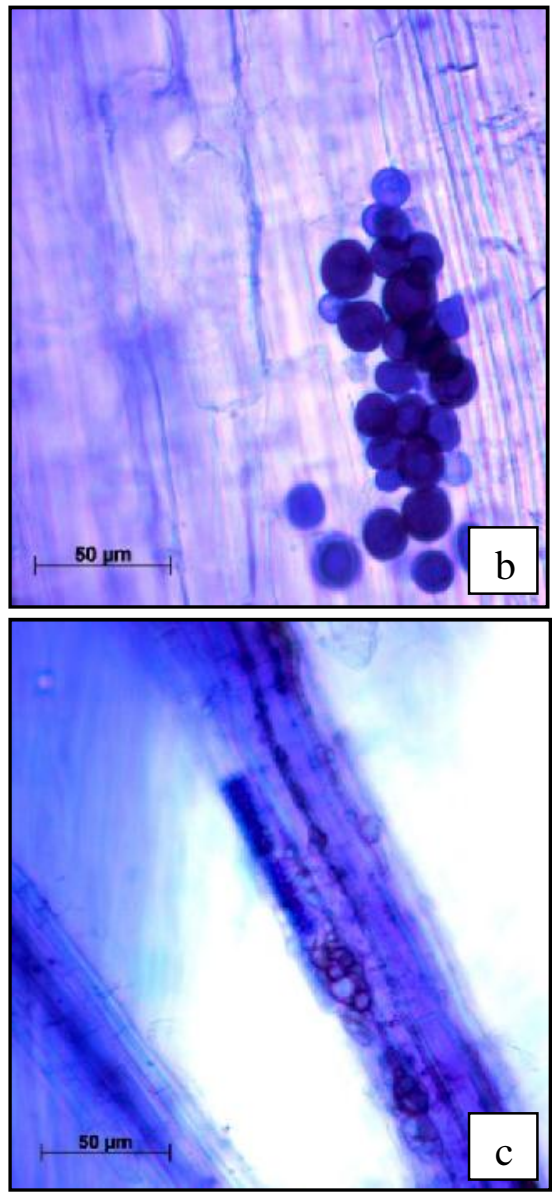

Gambar 3. Variasi struktur DSE yang ditemukan. Stuktur mirip klamidospora (a dan b), c mikrosklerosium mirip otak

Cendawan endofit berhasil diisolasi dari akar tanaman padi dan jagung. Jumlah cendawan endofit yang berhasil diisolasi dari akar jagung dan padi secara berturutturut adalah 8 dan 9 isolat. Namun dari ke 17 isolat tersebut hanya 1 jenis DSE yang berhasil diisolasi. Hal ini mungkin disebabkan media yang dipakai tidak terlalu mampu menunjang pertumbuhan DSE. Hasil isolasi DSE disajikan pada Gambar 4.

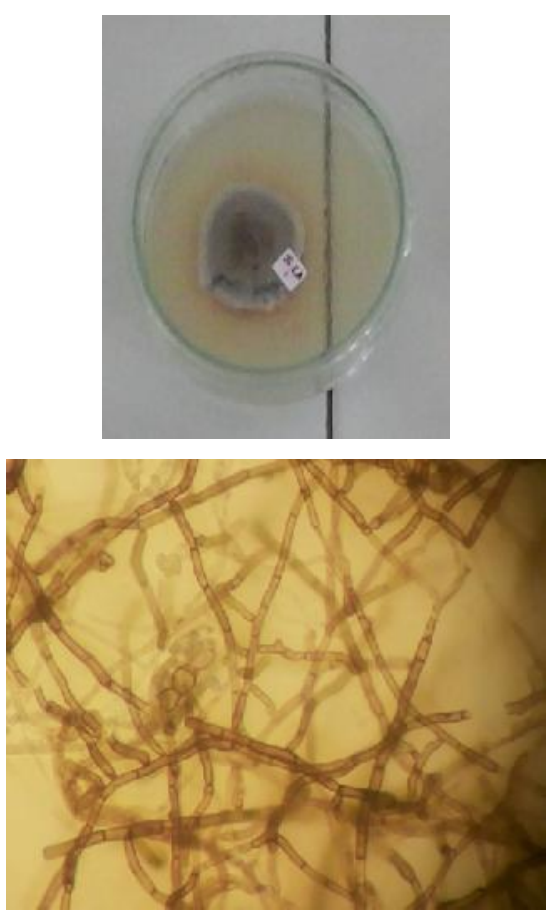

Gambar 4. Hasil isolasi DSE pada media PDA dan foto mikroskopis. Perbesaran 400x.

Pengamatan DSE langsung pada akar tanaman inang menggunakan pewarna biru tripan menunjukkan adanya variasi struktur DSE. Namun, setelah dilakukan isolasi menggunakan media PDA hanya ada satu isolat DSE yang ditemukan. Kesulitan melakukan isolasi ini kemungkinan besar disebabkan oleh penggunaan media yang kurang cocok untuk pertumbuhan DSE.

\section{KESIMPULAN DAN SARAN}

Karakteristik DSE yang ditemukan pada akar tanaman jagung dan padi beragam. Dua struktur umum yang ditemukan adalah hifa bersekat termelanisasi dan mikrosklerosium. Selain itu juga ditemukan struktur mirip klamidospora dan satu struktur mikrosklerosium unik yang mirip dengan otak (brainlike microsklerotium). 


\section{DAFTAR PUSTAKA}

Addy HD, Piercey MM, Currah RS. 2005. Microfungal endophytes in roots. Canadian Journal of Botany 83: 1-13.

Barrow JR, Aaltonen RE. 2001. Evaluation of the internal colonization of Atriplex canescens (Pursh) Nutt. roots by dark septate fungi and the influence of host physiological activity. Mycorrhiza 11: 199-205.

Barrow JR, Osuna P. 2002. Phosphorus solubilization and uptake by dark septate fungi in fourwing saltbush, Atriplex canescens (Pursh) nutt. J Arid Environ 51:449-459.

Butler MJ, Day AW. 1998. Fungal melanins: a review. Can. J. Microbiol., 44 (12):1115-1136.

Girlanda M, Ghignone S, Luppi AM. 2002. Diversity of sterile root-associated fungi of two Mediterranean plants. New Phytol., 155: 481-498.

Handayani D. 2016. Keberadaan cendawan dark septate endophyte (DSE) pada system perakaran benih Shorea selanica. Eksakta. 1: 38-44.

Horton TR, Cázares E, Bruns TD. 1998. Ectomycorrhizal vesicular-arbuscular and dark septate fungal colonization of bishop pine (Pinus muricata) seedlings in the first 5 months of growth after wildfire. Mycorrhiza, 8:11-18.

Jumpponen A, Mattson KG, Trappe JM. 1998. Mycorrhizal functioning of Phialocephala fortinii : interactions with soil nitrogen and organic matter. Mycorrhiza 7: 261-265.
E-ISSN : 2549-7464, P-ISSN : 1411-3724

Jumpponen A, Trappe JM. 1998. Dark septate endophytes: a review of facultative biotrophic root colonizing fungi. New Phytol 140:295-310.

Knapp D.G., Kovács G.M., Zajta E.,. Groenewald J.Z., P.W. Crous. 2015. Dark septate endophytic pleosporalean genera from semiarid areas. Persoonia 35:87-100.

Kormanick PP, McGraw AC. 1982. Quantification of VesicularArbuscular Mycorrhiza in Plant Roots. St Paulus: The American Phytophatology Society.

Mandyam K, Jumpponen A. 2005. Seeking the elusive function of rootcolonising dark septate endophytic fungi. Studies in Mycology. 53: 173-189.

Mandyam KG, Jumpponen A. 2015. Mutualism-parasitism paradigm synthesized from result of rootendophyte models. Hypothesis and Theory Article. 1: 13.

Lukešová, $\mathrm{T}$, Kohout $\mathrm{P}$, Větrovský $\mathrm{T}$, Vohník M. 2015. The potential of dark septate endophytes to form root symbioses with ectomycorrhizal and ericoid mycorrhizal Middle European forest plants. Plos One. 10(4): 1-25.

Rains KC, Nadkarni NM, Bledsoe CS. 2003. Epiphytic and terrestrial mycorrhizas in a lower montane Costa Rican cloud forest. Mycorrhiza, 13:257-264.

Robinson CH. 2001. Cold adaptation in Arctic and Antarctic fungi. New Phytol., 151: 341-353.

Scervino JM, Gottlieb A, Silvani VA, Pérgola M, Fernández L, Godeas AM. 2009. Exudates of dark septate endophyte (DSE) modulate the 
development of the arbuscular mycorrhizal fungus (AMF) Gigaspora rosea. Komunikasi singkat. Soil Bio Biochem 41:1753-1756.

Seerangan K \& Thangavelu M. 2014. Arbuscular mycorrhizal and dark septate endophyte fungal associations in South Indian Aquatic and Wetland macrophytes. J. Botany. 2014. Hindawi Publishing Corporation.

Silvani VA, Fracchia S, Fernández L, Pérgola M, Godeas A. 2008. A simple method to obtain endophytic microorganisms from field-collected roots. Soil Biol. Biochem., 40: 12591263.

Suryanarayanan TS, Ravishankar JP, Venkatesan G, Murali TS. 2004. Characterization of the melanin pigment of a cosmopolitan fungal endophyte. Mycol. Res., 108:974-978.

Usuki F, Narisawa K. 2007. A mutualistic symbiosis between a dark septate endophytic fungus, Heteroconium chaetospira, and a nonmycorrhizal plant, Chinese cabbage. Mycologia 99(2):175-184.

Vrålstad T, Schumacher T, Taylor A FS. 2002. Mycorrhizal synthesis between fungal strains of the Hymenoscyphus ericae aggregate and potential ectomycorrhizal and ericoid hosts. New Phytol., 153:143-152.

Yuan ZL, Zhang CL, Ling FC, Kubicek CP. 2010. Identity, diversity and molecular phylogeny of the endophytic mycobiota in the roots of wild rice (Oryza granulate) from nature reserve in Yuan, China. Appl. Environ. Microbiol.76(5) : 1642-1652
E-ISSN : 2549-7464, P-ISSN : 1411-3724

Zhang FD, He YM, Zu YQ, Li T, Zhao ZW. 2011. Characterization of melanin isolated from a dark septate endophyte (DSE), Exophiala pisciphila. World J. Microbiol. Biotechnol., 27: 2483-2489. 